\title{
Plasmodium vivax in Papua New Guinea: high diversity and gene flow among endemic populations signal roadblocks for elimination
}

\author{
Cristian Koepfli $^{1 *}$, Ivo Mueller ${ }^{2,3}$, Peter Siba ${ }^{2}$, Ingrid Felger ${ }^{1}$ \\ From Challenges in malaria research \\ Basel, Switzerland. 10-12 October 2012
}

The highest prevalence of Plasmodium vivax is observed in the lowlands of Papua New Guinea (PNG), the only country in the Western Pacific Region that experienced an increase in malaria cases over the last decade. Contrastingly, prevalence is lower in the Solomon Islands, a country aiming to eliminate malaria, where the number of confirmed cases decreased by approximately $50 \%$ from 2000 to 2010.

Population structure can inform interventions against malaria. Genetic diversity, gene flow and linkage disequlibrium (LD) between loci are thought to influence the emergence and spread of drug resistance and may affect efficiency of future vaccines. In endemic areas where transmission has been reduced to low levels, genotyping could play an important role in tracking outbreaks and to identify the origin of imported malaria cases.

In areas of a $P$. vivax endemicity lower than in PNG considerable genetic differentiation between populations was found, suggesting limited gene flow. To understand the population genetic structure of $P$. vivax in the South Pacific, we have used 14 molecular markers to genotype 295 P. vivax samples from four sites in PNG and from the Solomon Islands. Diversity was very high, with expected heterozygosity values ranging from 0.62 to 0.98 for the different markers. As a result, the effective population size was also found to be high. Among the four PNG sites, a near absence of population structure was observed $\left(F_{\mathrm{s} \tau}<\right.$ 0.015). When comparing PNG and the Solomon Islands, population structure was found to be weak $\left(F_{\mathrm{s} \tau}=0.03\right.$ to 0.044).

P. vivax populations in the South Pacific are much less structured than populations from areas of lower

${ }^{1}$ Swiss Tropical and Public Health Institute, Basel, Switzerland

Full list of author information is available at the end of the article endemicity in Latin America and Asia. In PNG, the presence of a large $P$. vivax reservoir seem to overcome the geographical barriers to transmission. Intensified, sustained control programs, which are coordinated among endemic countries and also target asymptomatic carriers, seem to be required to eliminate $P$. vivax in the South Pacific.

\section{Author details}

'Swiss Tropical and Public Health Institute, Basel, Switzerland. ${ }^{2}$ PNG Institute of Medical Research, Goroka, Papua New Guinea. ${ }^{3}$ Walter and Eliza Hall Institute, Parkville, Victoria, Australia.

Published: 15 October 2012

doi:10.1186/1475-2875-11-S1-024

Cite this article as: Koepfli et al:: Plasmodium vivax in Papua New Guinea: high diversity and gene flow among endemic populations signal roadblocks for elimination. Malaria Journal 2012 11(Suppl 1):O24.

Submit your next manuscript to BioMed Central and take full advantage of:

- Convenient online submission

- Thorough peer review

- No space constraints or color figure charges

- Immediate publication on acceptance

- Inclusion in PubMed, CAS, Scopus and Google Scholar

- Research which is freely available for redistribution 